\title{
A Special Case Of A Broken Heart
}

Shuwei Wang, MD

Thomas Jefferson University, shuwei.wang@jefferson.edu

Follow this and additional works at: https://jdc.jefferson.edu/tmf

Part of the Medicine and Health Sciences Commons Let us know how access to this document benefits you

\section{Recommended Citation}

Wang, MD, Shuwei (2015) "A Special Case Of A Broken Heart," The Medicine Forum: Vol. 16 , Article 5. DOI: https://doi.org/10.29046/TMF.016.1.004 Available at: https://jdc.jefferson.edu/tmf/vol16/iss1/5

This Article is brought to you for free and open access by the Jefferson Digital Commons. The Jefferson Digital Commons is a service of Thomas Jefferson University's Center for Teaching and Learning (CTL). The Commons is a showcase for Jefferson books and journals, peer-reviewed scholarly publications, unique historical collections from the University archives, and teaching tools. The Jefferson Digital Commons allows researchers and interested readers anywhere in the world to learn about and keep up to date with Jefferson scholarship. This article has been accepted for inclusion in The Medicine Forum by an authorized administrator of the Jefferson Digital Commons. For more information, please contact: JeffersonDigitalCommons@jefferson.edu. 


\title{
A Special Case Of A Broken Heart
}

\author{
Shuwei Wang, MD
}

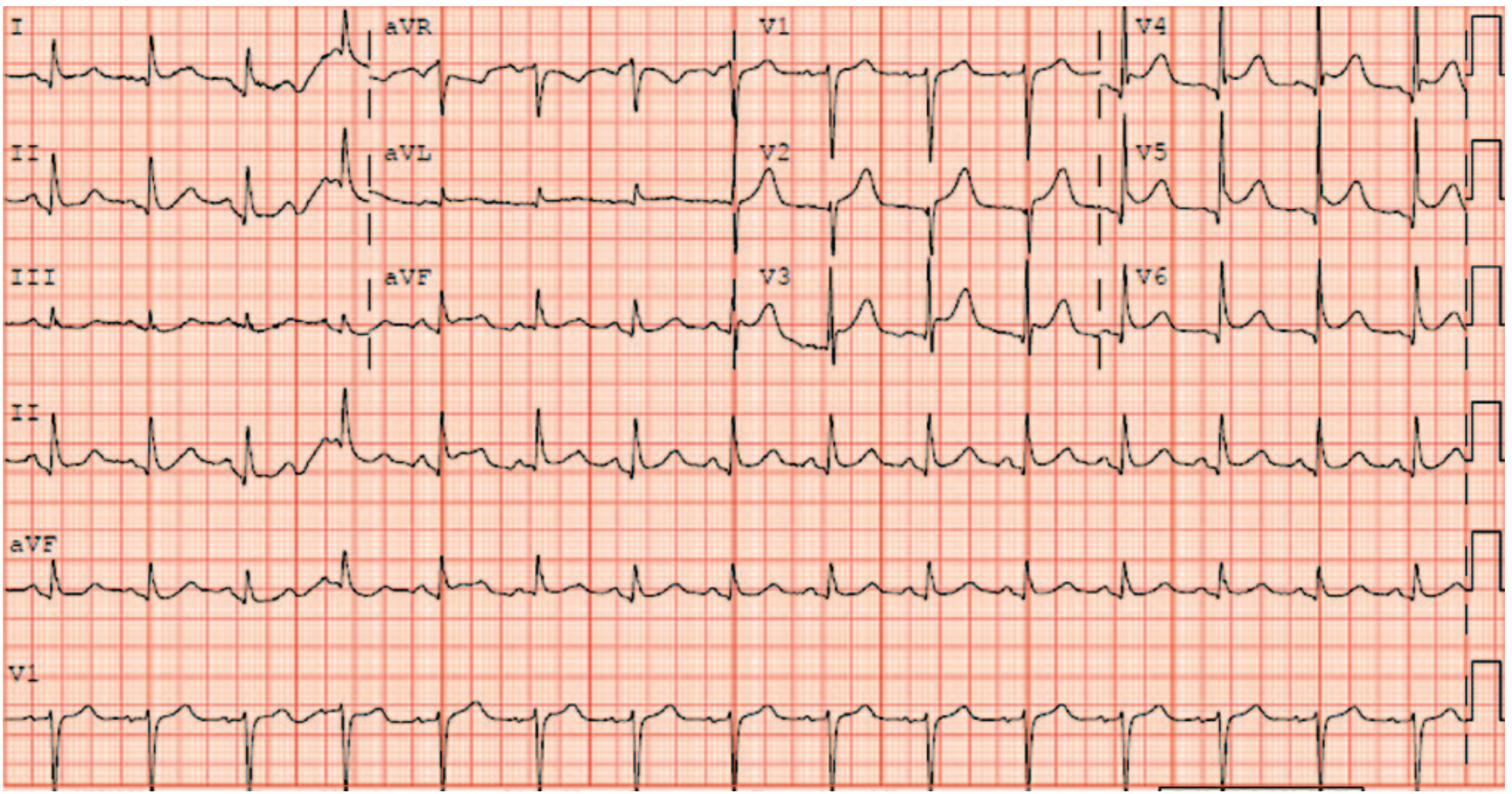

Figure 1. Mrs. S's initial EKG showing ST segment elevations in leads V2-V6.

\section{INTRODUCTION}

Takotsubo cardiomyopathy (TC), also known as stress cardiomyopathy, and broken heart syndrome is characterized by transient left ventricular (LV) apical akinesis with symptoms mimicking acute coronary syndrome. The first case was described by Sato et al. in Japan. ${ }^{1}$ The Japanese word "takotsubo" translates to "octopus pot" describing the shape of the left ventricle during systole. TC can be triggered by a "broken heart" including death of a loved one, constant anxiety, surgery, or critical illness etc. Prevalence is around $2 \%$ to $3 \%$ with over $90 \%$ in postmenopausal women aged between 58 and 75. Its pathogenesis remains unclear. Some postulated that excess catecholamine released during stress can induce an exaggerated sympathetic response precipitating severe, reversible LV dysfunction in patients without coronary disease. ${ }^{2}$ Whether there is a genetic component is not well understood. There are a few reported cases of Takotsubo in family members, one case of two sisters and another mother-daughter pair. ${ }^{3 .}$ Recurrence of the syndrome in the same patient, although rare, can occur and suggests a genetic predisposition.
Majority of patients regain normal ventricular function within one to four weeks if they survive the acute episode. Hospital mortality rates range from 0 to $8 \%$. However, one major complication is the risk of intraventricular thrombus formation and systemic embolization. Data is lacking to guide anticoagulation for LV thrombus prevention in patients with stress cardiomyopathy.

\section{CASE PRESENTATION}

Mrs. $S$ is a 62 year old woman with a prior history of TC with full recovery, hyperlipidemia, and gastroesophageal reflux disease presented with chest pain radiating to her left shoulder. She was under significant financial stress during that week. Her pain was unrelieved with aspirin or sublingual nitroglycerin. In the emergency room, her electrocardiogram showed ST segment elevations in leads V2-V6 (Figure 1) with Troponin T 1.49ng/mL. She was immediately started on heparin and nitroglycerin drips and rushed to the catheterization laboratory. Coronary angiography did not reveal significant coronary disease but incidentally found elevated pulmonary 
wedge pressures. Upon transfer to the cardiac intensive unit, Mrs. S became hypotensive and norepinephrine was started. Her transthoracic echocardiogram (TTE) revealed moderately decreased LV systolic function with an estimated ejection fraction (EF) of $35 \%$, with segmental wall motion abnormalities, mid and distal akinesis of the LV and hyperkinesis of basal LV. There was a late-peaking LV outflow tract gradient of $77 \mathrm{~mm} \mathrm{Hg}$ consistent with severe, dynamic left ventricular outflow tract (LVOT) obstruction.

She had a prior episode of TC when her husband passed away three years ago. She also has a twin sister who suffered from TC a year ago when she lost her job. Unlike Mrs. S, she did not fully recover and required long term heart failure management.

\section{DIFFERENTIAL DIAGNOSIS}

Takotsubo was at the top of our differential given the patient's personal and family history and recent financial stress. The lack of significant coronary disease on LHC clinched the diagnosis of stress cardiomyopathy.

\section{OUTCOME AND FOLLOW-UP}

Mrs. S was diagnosed with TC with LVOT obstruction complicated by cardiogenic shock. The LVOT obstruction made treatment particularly difficult given that inotropes can worsen the obstruction. Due to tachycardia, she was switched from norepinephrine to phenylephrine. On day 2, Mrs. S developed hypoxia and was intubated and rushed to cath lab for intra-aortic balloon pump insertion. However, the procedure was aborted when her right heart catheterization numbers and vital signs improved. She continued to recover on supportive care and was successfully extubated on day 8 . Her repeat TTE showed recovery of systolic function (EF $70 \%$ ) but revealed a $2.3 \times 1.1 \mathrm{~cm}$ LV apical thrombus. Heparin drip and warfarin were initiated. On day 9, patient reported blurry vision and a left visual field defect that were persistent despite wearing her glasses. Although her head CT scan was negative for mass effect or stroke, her head MRI revealed a recent punctate infarction in the right occipital lobe. In addition, on day 11, Mrs. S developed intractable back pain and a CT Abdomen and Pelvis showed new wedge-shape perfusion defects in the right kidney consistent with infarcts.

\section{DISCUSSION}

This case has multiple teaching points. First, it is one of the few cases of a patient with a recurrence of Takotsubo as well as a twin sister who suffered from the same syndrome suggesting a possible genetic predisposition to stress cardiomyopathy. Second, it emphasizes the risk of intraventricular thrombus formation and systemic embolization in patients with $\mathrm{TC}$ and raises the important discussion on whether these patients should receive prophylactic anticoagulation.

Familial cases of stress cardiomyopathy are very rare. One case reports a 64 year old female diagnosed with TC when presented with sudden chest pain, elevated cardiac enzymes and ST elevations. Her elder sister developed TC one year prior with similar presenting symptoms. There are also several other reports of sisters with TC. Studies on genetic polymorphisms for Takotsubo have been inconclusive. One study found an association between patients with TC and beta 1 adrenoreceptor gene polymorphisms, suggesting possible genetic disease modifiers for developing TC. ${ }^{6}$ However, a large Australian study did not find any association between functional variants in the G-protein-coupled receptor kinase 5 genes or the $\beta 1$-adrenergic receptor with the occurrence of the syndrome?

More research is also needed to understand the risk and prevention of thromboembolism in TC patients. In a Japanese study of 21 patients with Takosubo, they found that 3 patients (14\%) suffered thromboembolism, one of which had a LV thrombus. They recommended prophylactic anticoagulation for TC patients with severe wall motion abnormality to prevent cardioembolic stroke ${ }^{8}$.

There are scant data on criteria for prophylactic anticoagulation to prevent thromboembolism in TC. In patients with myocardial infarction, it has been found that reperfusion therapy and anticoagulant therapy lowers the risk of thrombus formation, which would also lower the risk of thrombus embolization. In a 1993 meta-analysis in patients who had an anterior MI, the odds ratio of LV thrombus in patients treated with fibrinolytic was half compared to no fibrinolytic therapy. ${ }^{9}$ The same study also showed that initiating heparin early and for more than 48 hours lowered the rate of thrombus formation. In a randomized control trial, high dose (12,500 units) subcutaneous unfractionated heparin given every 12 hours for 10 days was associated with lower incidence 
of LV thrombus compared to low dose (5,000 units). (11 versus 32 percent)..$^{10}$ Amongst patients who already developed a LV thrombus, anticoagulation with warfarin lowers the risk of thrombus embolization. An observational study of 43 patients with LV thrombus after MI found no embolic events in the 25 patients treated with anticoagulation compared to 7 of 18 untreated patients having an embolic event, all occurring within 4 months. ${ }^{11}$ Although no studies have been done on patients with stress cardiomyopathy, it would be reasonable to initiate anticoagulation in patients with severe LV dysfunction to prevent thrombus.

\section{KEY POINTS}

1. Familial and recurrent cases suggest a genetic predisposition to Takotsubo cardiomyopathy.

2. Patients suffering from stress cardiomyopathy with severe LV dysfunction may benefit from early anticoagulation to prevent thromboembolism.

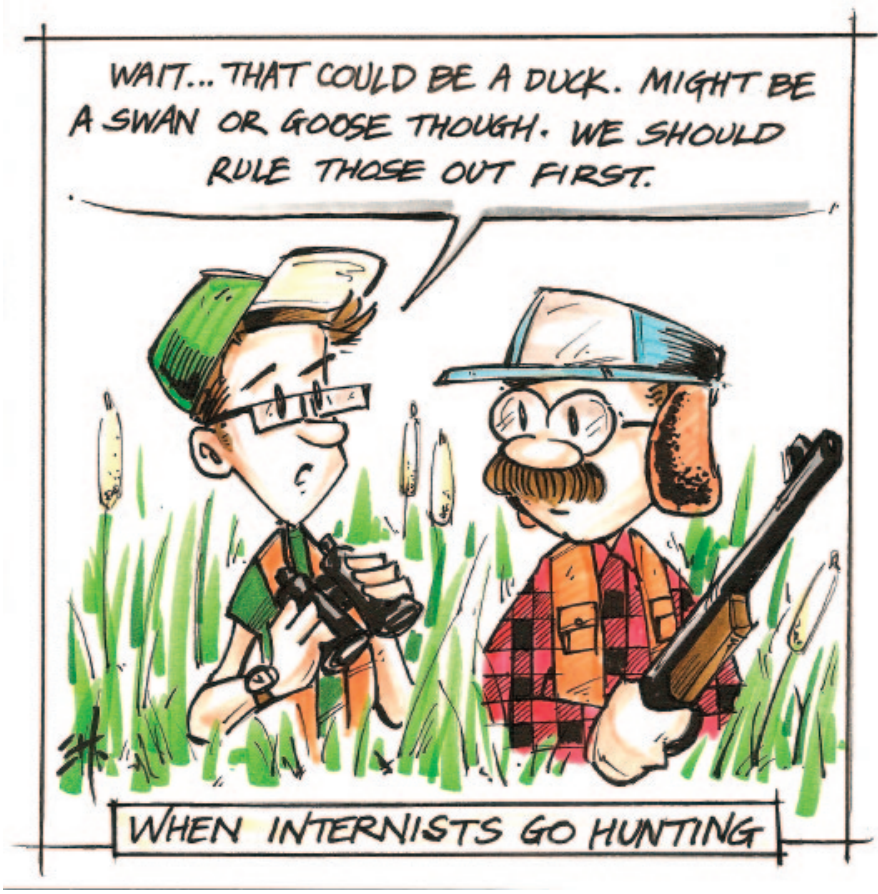

\section{REFERENCES}

1. Sato H, Taiteishi H, Uchida T. Takotsubo-type cardiomyopathy due to multivessel spasm. In: Clinical aspect of myocardial injury: From ischemia to heart failure, Kodama K, Haze K, Hon M (Eds), Kagakuhyouronsha, Tokyo 1990. p.56.

2. Wittstein IS, Thiemann DR, Lima JA, et al. Neurohumoral features of myocardial stunning due to sudden emotional stress. N Engl $\mathrm{J}$ Med 2005; 352:539.

3. Ikutomi M, Yamasaki M, Matsusita M, et al. Takotsubo cardiomyopathy in siblings. Heart Vessels 2014; Jan;29(1):119-22.

4. Subban V, Ramachandran S, Victor SM, et al. Apical ballooning syndrome in first degree relatives. Indian Heart J. 2012 Nov-Dec;64(6):607-9.

5. Eitel I, Moeller C, Graf T, et al. Recurrence of takotsubo cardiomyopathy with different ballooning patterns. Int J Cardiol. 2014 Nov 15:177(1):25-6

6. Vriz O, Minisini R, Citro R, et al. Analysis of beta1 and beta2-adrenergic receptors polymorphism in patients with apical ballooning cardiomyopathy. Acta Cardiol. 2011 Dec;66(6):787-90.

7. Figtree GA, Bagnall RD, Abdulla l, et al. No association of G-protein-coupled receptor kinase 5 or $\otimes$-adrenergic receptor polymorphisms with Takotsubo cardiomyopathy in a large Australian cohort. Eur J Heart Fail. 2013 Jul;15(7):730-3.

8. Weinreich DJ, Burke JF, Pauletto FJ. Left ventricular mural thrombi complicating acute myocardial infarction. Long-term follow-up with serial echocardiography. Ann Intern Med 1984; 100:789.

9. Vaitkus PT, Barnathan ES. Embolic potential, prevention and management of mural thrombus complicating anterior myocardial infarction: a meta-analysis. J Am Coll Cardiol 1993; 22:1004.

10. Turpie AG, Robinson JG, Doyle DJ, et al. Comparison of high-dose with low-dose subcutaneous heparin to prevent left ventricular mural thrombosis in patients with acute transmural anterior myocardial infarction. N Engl J Med 1989; 320:352

11. Mitsuma W, Kodama M, Ito M, Kimura S, Tanaka K, Hoyano M, et al. Thromboembolism in Takotsubo cardiomyopathy.. Int J Cardiol. 2010 Feb 18;139(1):98-100

Cartoon by Eugene Han, MD 